\title{
Counterfactuals and Antirealism
}

\author{
Panayot Butchvarov* \\ The University of lowa USA \\ *Corresponding Author \\ Panayot Butchvarov

\section{Article History} \\ Received: 12.07.2019 \\ Accepted: 24.07.2019 \\ Published: 30.07 .2019
}

\begin{abstract}
There could be no causal connections in the world because if there were there would be counterfactual facts, and there are no such facts. Cognition of the world must employ counterfactual statements, roughly of the form "If $p$ were true, then $q$ would be true," but obviously there are no counterfactual facts.
\end{abstract}

Keywords: cognition, antirealism, causality, counterfactual

\section{The ways to antirealism}

Metaphysical antirealism is seemingly incredible but, paradoxically, also self-evident. It seems self-evident insofar as it says that if there is a world that we do not and cannot cognize (Kant's "things-in-themselves") then we can ignore it, and if there is a world that we do or at least can cognize (Kant's "things-for-us") then it can only be the world as we do or can cognize it. So the world we do cognize seems, in a sense, dependent on our cognition of it. (We may think of cognition as the capacity for knowledge, and of knowledge as the successful exercise of that capacity.) Metaphysical antirealism is not solipsistic - it's about what we, not what I, do or can cognize. For cognition of a world, unlike cognition of a toothache but like cognition of physics, mathematics, geography, or history, is inseparable from others' cognition - from the common language we speak to most of the views we espouse. It is collective. It does involve feeling and perception, but consists mostly in understanding and speaking. Wittgenstein did write, "The limits of my language mean the limits of my world," 1 but as he saw later it would be more accurate to say that they are the limits of our world.

Yet metaphysical antirealism also seems incredible because we think of ourselves as only tiny parts of the world, hardly its creators. To make it credible, we must steer away from the usual abstract generalities (e.g., "to be is to be perceived") and misleading metaphors (e.g., "we make the world"), and find ways leading to it that are specific and clear. The most powerful way is roughly Wittgensteinean. It points out that the world must have a logical structure, i.e., it must be describable in logically coherent sentences, yet that the "logical constants do not represent2". A second, quasi-logical way, noticed centuries ago by Antoine Arnauld, casts doubt even on a fundamental part of logic. It points out that although advanced cognition requires generalization, ordinarily we must confine ourselves to generic, not universal, statements: we seldom seriously assert statements of the form approved by logic "All Fs are G," and use instead statements of the disapproved form "Fs are G." We say "Dutchmen are good sailors," rather than "All Dutchmen are good sailors," because the latter would be too strong, while the also approved "Some Dutchmen are good sailors" would be too weak and " $\mathrm{x} \%$ of Dutchmen are good sailors" too precise [3]. Indeed, generic statements are not reducible to any statements approved by logic, yet they remain indispensable to our cognition of the world. What do they mean? They just mean what they say: e.g., that Dutchmen are good sailors.

I have discussed these specific ways to antirealism in detail elsewhere, as well as how antirealism can avoid the absurd anthropocentrism it seems to imply[ $\left.{ }^{4}\right]$. My topic here is a third way. It is roughly Kantian. To be understood, not just felt, the world must

\footnotetext{
${ }^{1}$ Ludwig Wittgenstein, Tractatus Logico-Philosophicus, trans. D. F. Pears and B. F. McGuinness (London: Routledge, 1972), 5.6.

2 Tractatus Logico-Philosophicus 4.441

${ }^{3}$ The example is Arnauld's. See Antoine Arnauld and Pierre Nicole, Logic or the Art of Thinking, translated and edited by Jill Vance Buroker, Cambridge: Cambridge University Press, 1996, p. 116. Generic statements have aroused much interest in contemporary linguistics. See, for example, Gregory N. Carlson and Francis Jeffry Pelletier, eds., The Generic Book (Chicago: University of Chicago Press, 1995).

4 Panayot Butchvarov, "Metaphysical Realism and Logical Antirealism," in Richard Gale, ed., Guide to Metaphysics (Oxford: Blackwell, 2002), and Anthropocentrism in Philosophy. Realism, Antirealism, Semirealism (Boston/Berlin: De Gruyter, 2015).
}

Copyright @ 2019: This is an open-access article distributed under the terms of the Creative Commons Attribution license which permits unrestricted use, distribution, and reproduction in any medium for non commercial use (NonCommercial, or CC-BY-NC) provided the original author and source are credited. 
have not only a logical but also a causal structure; to cognize something we must understand not only what but also why it is. Yet there could be no causal connections in the world because if there were there would be counterfactual facts, and there are no such facts. Cognition of the world must employ counterfactual statements, roughly of the form "If $p$ were true, then q would be true," but obviously there are no counterfactual facts.

Of course, the antirealist does not claim that cognition creates the world, that objects corresponding to the logical constants and facts corresponding to generic and counterfactual statements are created by our cognition of them,. Goodman's phrase "worldmaking" is at best a misleading metaphor [5]. Kant was clearer and explicit: "[T]he categories do not afford us cognition of things by means of intuition except through their possible application to empirical intuition, i.e., they serve only for the possibility of empirical cognition [6]." The category of causality, for example, does not miraculously create a necessary connection between events; it only allows us to understand their conjunction as causal, i.e., necessary.

Kant also wrote, "[The] possibility [of general laws of nature] has its ground merely in the relation of the understanding to experience, however, not in such a way that they are derived from experience, but that experience is derived from them[7]." The causal structure of the world is derived not from our perception but from our understanding, conceptualization, of the world. Nothing would be an understandable world if it lacked a causal structure: to understand anything in the world we must ask "Why is it?" Similarly, nothing would be a world if it lacked logical structure; to understand anything in the world we must also ask "What is it?" But there is nothing in the world corresponding to the logical constants and syntactical relations that are essential to every statement about the world. These are clear and specific arguments for antirealism that seem much more plausible than the usual abstract arguments from the nature of perception or the workings of language. The argument from the ubiquity of generic statements is also specific though perhaps less clear.

Antirealism is not nihilism, nor is it skepticism. Its thesis is neither that there is nothing, nor that we know nothing. It is that what is known, the "world," is inseparable from our knowledge, or more generally our cognition, of the world. An antirealist interpretation of counterfactuals, therefore, does not claim that no counterfactuals are true. It claims that their truth is not due to there being corresponding things or facts in the world that would be there even if there were no counterfactual statements or judgments. Similarly, logical constants and syntactical relations are essential parts of all statements about the world, but it is evident that they correspond to nothing in the world, that there are no such things as and, or, and all in the world. Our topic here is the role of counterfactuals in cognition as a route to metaphysical antirealism. But let me repeat that it is not the only route. Another, perhaps more obvious, is the role of the logical expressions. Less obvious, though no less decisive, is our unavoidable reliance on generic statements.

Our cognition of the world, if at all advanced, does employ counterfactual conditionals, often explicitly, but mostly implicitly in the guise of causal statements. Whatever else causal statements involve, and even if causal relations are in some cases observable (as Evan Fales has argued $\left[{ }^{8}\right]$ ), they must be understood as entailing counterfactuals. Hume rejected the view that causal statements are about "relations of ideas," that they are analytic or logically true, denied that causation is an observable necessary connection between "impressions," suggested that "we may define a cause to be an object, followed by another, and where all the objects similar to the first are followed by objects similar to the second," but ended by appealing to the counterfactual "In other words, if the first object had not been, the second never existed[9]". Hume thought causal statements are epistemologically suspect, but as Quine later showed counterfactual statements are logically suspect.

What in the world, in "reality," could correspond to a counterfactual? If what its antecedent (as well as, perhaps, the consequent) says is not a fact, what makes the counterfactual true? It cannot be a relation between the facts that its antecedent and consequent express, for there is no fact the antecedent (as well as, perhaps, the consequent) expresses. Some counterfactuals are necessarily true, even a priori, whether tautologies such as "If Jack were married, he would not be a bachelor" or mathematical truths such as "If Jack had 5 dollars and Jane only 3 , then Jack would have more dollars than Jane," but they obviously inherit their truth from that of indicative statements, respectively, "If Jack is married then he is not a bachelor" and " 5 is greater than 3." And there are no readily available indicative statements from which most true counterfactuals, including those implied by causal statements, inherit their truth. What makes these counterfactuals true, then?

If the answer is "Nothing," as the very term "counterfactual" ("contrary-to-fact") suggests, then some form of metaphysical antirealism, whether Berkeley's subjective idealism, Kant's transcendental idealism, Hegel's absolute idealism, Wittgenstein's view that the things that matter most can be shown but not said, Goodman's irrealism, or what elsewhere I have called semirealism[10],

${ }^{5}$ Cf. Nelson Goodman, Ways of Worldmaking (Indianapolis: Hackett, 1978). I agree with the main thesis of the book but regret the author's metaphorical use of "making," which provoked, for example, the inconclusive exchange between him and Israel Scheffler (collected in Starmaking, ed. Peter J. McCormick, Cambridge: MIT Press, 1986), as well as his use of "world," which is not metaphorical but still unfortunate, for reasons I explain below.

${ }^{6}$ Immanuel Kant, Critique of Pure Reason, translated and edited by Paul Guyer and Alen W. Wood (Cambridge: Cambridge University Press, 2005$)$, p. 255.

7 Immanuel Kant, Prolegomena to any Future Metaphysics, § 30.

${ }^{8}$ Evan Fales, Causality and Universals (London: Routledge, 1990).

${ }^{9}$ David Hume, Enquiry concerning Human Understanding (Oxford: Oxford University Press, 1975), p. 76.

10 See Anthropocentrism in Philosophy. 
seems unavoidable, even if we manage to avoid the absurd anthropocentrism it seems to imply: that the whole universe depends on certain animals on one of its planets. It can never seem true, let alone be part of common sense, that there are no trees that none of us perceives (Berkeley), or that space and time belong only to the subjective constitution of the human mind (Kant)[11], or that the whole world is in some sense made by us (Goodman). But it does seem obvious, perhaps even part of common sense, that there are no facts that are counterfactual.

\section{Counterfactual conditionals}

Let's recall how the meaning and truth-value of counterfactuals are judged in common sense and in science. Quine, no friend of counterfactuals, distinguished the subjunctive conditional, which he says is "intruded" by "a stabilizing factor," from both the material conditional, which is understood truth-functionally (e.g., as true whenever the antecedent is false, regardless of the truth-value of the consequent), and the indicative conditional of ordinary usage. He suggested, regarding "If a were in water at $t$, a would dissolve at $t$," that there is the intrusion as stabilizing factor of "a theory of subvisible structure." Our regarding that theory as true may explain why we regard the counterfactual as true [12]. But it's an open question whether that theory does not itself include explicit or implicit causal statements, our understanding of which, as Hume saw, would require appeal to counterfactuals.

At any rate, no theory is available the intrusion of which would help us in the case of the statement "If Hitler had not invaded the USSR, Germany would not have lost World War Two." In the case of the statement "If John had not taken that flight, he would not have been killed," perhaps there is a theory about what happens to passengers in airplane crashes. But it is a causal theory. It would be better to just say that the "stabilizing factor' in the case of such a counterfactual is the context in which the statement is made: the relevant facts, implicit premise(s), general background, etc. Its "intrusion" explains our belief that the statement "If a were in water at $t$, a would dissolve at $t$ " is true, while the absence of such a context in the case of the statement "If a were in water at $t$, a would turn into a mermaid at t" or "If Hitler had not invaded the Soviet Union then that blue book would have been yellow" would make the statement so peculiar as to be judged not so much as false as senseless.

But a counterfactual is not reducible to the propositions constituting its context. Therefore, even if a realist interpretation of these propositions is unquestioned, a realist interpretation of counterfactuals remains implausible. In neither case would we have made progress in our understanding what the counterfactual means and, if true, what makes it true.

\section{Possible worlds}

We would gain little by appealing to "possible worlds," "full-blooded physical beings, universes like ours," inhabited not by the objects in our world but by "counterparts" of them [13]. We would gain even less if we just called them "ways things could have been," as David Lewis does [14]. We would learn little from being told then that "counterfactuals have to do with what goes on at [such] possible worlds given jointly by the antecedent, factual background, and contextual influences [15]." The range of possible worlds is even more intimidating than the range of the possible consequences of a single action. And it is an illusion to think that we can identify a possible world by means of a definite description such as "The possible world in which the Queen of England is murdered." There would be not one but a countless number of such possible worlds. Think of the various plots of possible novels in which the Queen of England is murdered.

Lewis also wrote: "The counterfactual ['it is the case at W that if $c$ had not occurred, e would not have occurred either'] means that at the closest worlds to $w$ at which $c$ does not occur, e does not occur either ${ }^{16}$ ". He explained the "closeness" of worlds in terms of their similarity, the mention of 'the closest world' presumably intended to replace a vacuous reference to "the context, relevant facts, implicit premise(s), sets of beliefs, laws of nature, factual background, purposes, assumptions, etc." that must be taken into account. But referring to "closest worlds" does not avoid vacuity, and only increases our befuddlement. The range of close possible worlds is not less intimidating than the range of the logically possible consequences of a contemplated action.

Regarding such views, Saul Kripke remarked, "Of course when we specify a counterfactual situation, we do not describe the whole possible world, but only the portion that interests us [17]." And, as to Lewis's counterpart theory, he wrote, "Possible worlds' are

\footnotetext{
11"We can ... speak of space, extended things, and so on, only from the human standpoint" (Immanuel Kant, Critique of Pure Reason, trans. Paul Guyer and Allen W. Wood (Cambridge: Cambridge University Press, 1998, B 42-44).

12 Willard Van Orrman Quine, Word \& Object (Cambridge, Mass.: The MIT Press, 1960), pp. 222-23. "The subjunctive conditional," Quine wrote, "depends, like indirect quotation and more so, on a dramatic projection: we feign belief in the antecedent and see how convincing we then find the consequent. What traits of the real world to suppose preserved in the feigned world of the contrary-to-fact antecedent can be guessed only from a sympathetic sense of the fabulist's likely purpose in spinning his fable" (p. 222.)

${ }^{13}$ Alexander R. Pruss, "The Actual and the Possible," in Richard M. Gale, ed., The Blackwell Guide to Metaphysics (Oxford: Blackwell, 2002$)$, p. 321.

14 David Lewis, Counterfactuals (Cambridge, Mass.: Harvard University Press, 1973), p. 84. However controversial, Lewis's appeal to possible worlds is a genuine metaphysical attempt at explanation of everyday talk about possibilities and necessities, not, as Robert Stalnaker puts it, just "a paraphrase [of it] in an extensional language" ("Reference and Necessity," in A Companion to the Philosophy of Language, eds. Bob Hale and Crispin Wright, Oxford: Blackwell, 1997. p. 539).

15 David Lewis, On the Plurality of Worlds (Oxford: Blackwell, 1986), p. 22.

16 On the Plurality of Worlds, p.78.

17 Saul A. Kripke, Naming and Necessity (Cambridge, Mass.: Harvard University Press, 1980), p. 49.
} 
stipulated, not discovered by powerful telescopes. There is no reason why we cannot stipulate that, in talking about what would have happened to Nixon in a certain counterfactual situation; we are talking about what would have happened to him[18]."

Of course, the limited worth of talk about possible worlds does not affect the technical interest of modal logic. And the often ingenious work in quantified modal logic does call for admiration [ $\left.{ }^{19}\right]$. But its fealty to the $20^{\text {th }}$ century linguistic turn can be appalling. For example, counterfactuals need not be sentences. They could be judgments or thoughts. If involved in a car accident this morning, I might think, without saying it, that if I had not been in my car this morning I would not have been in that accident. Surely children entertain such thoughts long before mastering the syntax of counterfactual talk.

And skepticism about possible worlds need not be skepticism about possible individuals, properties, or states of affairs. We do talk and, more importantly, think about Pegasus, Hamlet, the monster I saw in a dream, tastes no one ever tasted or will taste, etc. So there are nonexistent but possible things. Do they exist in some possible world? One would ask, "Which world?" And, of course there is no answer. To say, "in some possible world," would be like saying that Mary lives in some town, and when asked "Which town?" to be told that it is the town where Mary lives. It is not about nonexistent possible things but about possible worlds that we seldom (if ever) talk or think - perhaps because to distinguish such a world from other possible worlds would seem to require thinking about all of its constituents, whether things or facts, a feat of which God presumably is capable but surely we are not.

\section{The World}

The deeper flaw in appealing to possible worlds is not its reliance on the notion of possibility but rather its reliance on the philosophical notion of a world, which must not be confused with the everyday notion commonly defined by dictionaries as meaning the earth or the universe. That philosophical notion is fatally defective, as Wittgenstein saw more than a century ago. It is mindboggling that in the vast literature on possible worlds so little is said about what the word "world" signifies. David Lewis just writes, "I can only ask [my questioner] to admit that he knows what sort of thing our actual world is, and then explain that other worlds are more things of that sort. Differing not in kind but only in what goes on at them [20]".

Is the world the totality of things, as we would usually suppose, or is it the totality of facts, as Wittgenstein held (Tractatus 1.1)? The metaphysical problems faced in answering this question are daunting. If the world is the totality of things, are minds and God included in it? If it is the totality of facts, are only atomic facts included, or also molecular and general facts? And what sort of entity is an atomic fact? Indeed, what is a fact?

Wittgenstein held that '[l]t is nonsensical to speak of the total number of objects. The same applies to the words 'complex', 'fact', 'function', 'number', etc. They all signify formal concepts" (Tractatus 4.1272). This would be true also of the concept 'world," regardless of whether the world is the totality of objects (things) or of facts, since "object" and "fact" are both formal concepts. ${ }^{21}$ The problem with talk about "the world" is logical. It is not that the world is too big or too unlike what we take it to be. Not its size or content but its logical/ontological category, or rather its failing to fall in any category, is what makes it mysterious. We may say that the world is everything, but this would be only to acknowledge its peculiarity. Moreover, to speak of everything is to implicitly employ the predicate "object" or "fact," depending on whether we think the world is the totality of objects ("things") or of facts. Both, Wittgenstein held, express only formal concepts, corresponding to formal or internal properties, and the sentences, in which they occur, he claimed, say nothing, even if they show much.

There is a reason for agreeing with Wittgenstein that "the world is the totality of facts, not of things." If Jack admires Jill but Jill does not admire Jack, what would distinguish the world in which this is so from the world in which Jill admires Jack but Jack does not admire Jill, the world in which they admire each other, and the world in which neither admires the other, if these worlds differed in no other respect? There would be no answer if we supposed that there are only individuals, properties, and relations in the world. Only the fact that Jack admires Jill but Jill does not admire Jack, not their mere presence in the world, including even the presence of a relation of admiration, would distinguish that world from the other three. Hence the conclusion that the world is the totality of facts.

There is also a reason for agreeing with Wittgenstein that the sentences in which the word "fact" occurs say nothing, even if they do show something. As P. F. Strawson wrote, "The only plausible candidate for what (in the world) makes a statement true is the fact it states; but the fact it states is not something in the world.... Of course, statements and facts fit. They were made for each other. If you prise the statements off the world you prise the facts off it too; but the world would be none the poorer.... Facts are not broken or overturned, interrupted or prolonged, kicked, destroyed, mended, or noisy." Strawson took the latter point to be relevant because he

\footnotetext{
${ }^{18}$ Naming and Necessity, p. 44. Kripke went on to say (in a footnote): It is better..., to avoid confusion, not to say, 'In a possible world, Humphrey would have won' but rather, simply, 'Humphrey might have won'. The apparatus of possible worlds has (I hope) been very useful as far as the set-theoretic model-theory of quantified modal logic is concerned, but has encouraged philosophical pseudo-problems and misleading pictures." (p. 48).

19 "The apparatus of possible worlds has (I hope) been very useful as far as the set-theoretic model -theory of quantified modal logic is concerned, but it has encouraged philosophical pseudo-problems and misleading pictures." (Kripke, Naming and Necessity, p. 48 n.)

${ }_{20}$ Counterfactuals, p. 85

21 We may note that the World was one of the three spurious objects of knowledge that Kant thought required treatment in the transcendental dialectic, the other two being the Self and God.
} 
believed that "the whole charm of talking of situations, states of affairs or facts as included in, or parts of, the world, consists in thinking of them as things, and groups of things[22]".

Of course, there are nominalizations of sentences, such as "Snow's being white" in the case of "Snow is white." They indeed are nouns and often do serve as subjects or objects of verbs. But they are not sentences and could not be taken to stand for facts even if there were facts. Consider the phrase "John's whistling" as it might occur in the sentence "John's whistling awoke her." It stands for a whistling, which is an action, a doing, perhaps just a noise, not for a fact. Hence the tendency to refer to facts instead with what Fowler called fused participles, like "Snow being white" or "John whistling awoke her." (Fowler's example was "Women having the vote reduce men's political power.") One of the two words in "John whistling" is presumably intended to modify the other; otherwise, they would be just a pair of unrelated words. But if "whistling" is intended to modify "John," then the grammatically proper sentence would be "Whistling John awoke her" or, better, "John, who was whistling, awoke her." Both are obviously different from "John's whistling awoke her" - they could be true when it is false and false when it is true. And if "John" is intended to modify "whistling," then the grammatically proper sentence would be the original "John's whistling awoke her," the subject-term of which refers to something John does or makes an action or a noise, not a fact. Contrary to Roderick Chisholm, Fowler's objection to fused participles was not a mere "stricture [23]." They are bad logic, not just bad grammar.

Semirealism. There is a third way of understanding facts, which is neither realist nor antirealist. It is semirealist, and is suggested by Wittgenstein's distinction between saying and showing. In general, if a proposition is in dispute between realism and antirealism, with the realist asserting and the antirealist denying it, the semirealist would differ from both by holding that it is an improper proposition, perhaps even that there is no such proposition, and thus that both asserting and denying it are improper. Now, as already noted, "fact" was on Wittgenstein's list of formal concepts. And according to him, "when something falls under a formal concept as one of its objects, this cannot be expressed by means of a proposition. Instead it is shown in the very sign for this object" (Tractatus 4.126). This is why it is "nonsensical" to speak of objects or facts - or of the world.

Going beyond what we find in Wittgenstein, we may think of what can be "said" as what ordinarily is taken as real independently of our cognition of it, and of what can only be shown as what cognition contributes to its reality. The latter is essentially structural, relational. This is why the controversies between the idealist F. H. Bradley and the realist Bertrand Russell focused on the reality of relations. Relations are the most striking example of what seems to be not a real entity, even when its relata are unquestionably real.

Hence the appropriateness of calling the position I have described as semirealism. Wherever "fact" is used as a proper concept-word, nonsensical pseudo-propositions would result, just as wherever "object" is used as a proper concept-word. The same can be said regarding the concept-word "world," regardless of whether the world is the totality of facts or of objects. It cannot be "said" that what the sentence "This page is white" asserts is a fact, for the same reason it cannot be said that this page is an object. To say "it is a fact" would be worse, because if we replaced the subject-term with a sentence, the resulting "This page is white is a fact," would be grammatically ill-formed. Of course, we may say "That this page is white is a fact," but "That this page is white" is not a sentence and thus not what the pronoun "it" refers to. We can no more intelligibly talk about facts than we can talk about objects. To this extent, antirealism regarding facts appears right. But this does not mean that Wittgenstein was an antirealist regarding facts.

When an item, say, what the true sentence "This page is white" allegedly corresponds to, falls under the formal concept "fact," this cannot be expressed by means of a proposition but neither is it nothing. For it is "shown" in the sign for the item, namely, the sentence. Just as "a name shows that it signifies an object, a sign for a number that it signifies a number" (Tractatus 4.126), a sentence shows that it signifies a fact. We cannot properly say "there are facts" but also cannot properly say "there are no facts," just as we cannot properly say "there are objects" but also cannot properly say "there are no objects." As argued earlier, the presence in the world of the individuals, properties, or relations mentioned in a true sentence does not suffice for its truth. "Jack admires Jill" mentions Jack, Jill, and the relation of admiration. But their presence in the world does not make it true. It does not distinguish the world in which the sentence is true from worlds in which the sentence is false but otherwise are just like it. Surely, however, there is such a distinction to be made. To this extent, realism regarding facts appears right. But this does not mean that Wittgenstein was a realist regarding facts.

His distinction between saying and showing is not mysterious. It is especially clear when we consider his view of a sentence as a logical picture (Tractatus 2.181). In a painting, much is shown that is not and cannot be pictured by the painting or by any part of it. For example, the painting may represent a tree next to a barn, each represented by a part of the painting, and the spatial relation between the parts of the painting that represent the tree and the barn would represent their relation of being next to each other. But nothing in the painting represents that relation's being a relation, nothing "says" that their being next to each other is a relation (rather

22 P. F. Strawson, "Truth," Aristotelian Society Supplementary Volume 24 (1950), 136-137. See also his "Reply to John R. Searle" in Lewis Edwin Hahn, The Philosophy of F. Strawson (Chicago \& LaSalle: Open Court, 1998), 402-04.

${ }^{23}$ Chisholm suggested that the objection was a mere stricture in his reply to my "States of Affairs," in Radu J. Bogdan, ed., Roderick M. Chisholm (Dordrecht: Reidel, 1986) 
than, say, a shape or color). Yet the painting shows this, indeed must show it in order to represent what it does represent. What it shows cannot be denied as one might deny, for example, that the painting is a portrait of Churchill. The absence from the painting of what it only shows would not be like Churchill's absence from it. Of course, paintings do not consist of words. But, like all pictures, physical or mental, paintings are also logical pictures, though not all logical pictures are paintings.

Semirealism regarding facts differs from realism regarding facts by denying that true sentences stand for special entities, which can be referred to, described, and analyzed independently of the sentences, and are additional to and categorially different from the entities mentioned in the sentences. This page is rectangular, white, made of paper, and held in our hands, but none of these can be said of the fact that the page is white. This is why antirealism regarding facts is plausible. But at least sentences reporting direct observation, like "That's a cat, not a dog," obviously are not true just in virtue of the words they contain, or of some relation they bear to other sentences, the speaker, a culture, or an institution. This is why realism regarding facts is plausible. If the correspondence theory of truth is defective, the reason is not that it distinguishes the sentence from the fact that makes it true but that it fails to acknowledge the special nature of facts, the special status of the concept of fact. If the world is supposed to be the ref facts, the notion of the world is infected with all the obscurity of the notion of fact, yet without the latter's virtue, namely, its direct connection with the notion of truth.

The problem with counterfactual conditionals is that there seem to be no counterfactual facts. But if "fact" is a formal concept, there seem to be no facts at all. Yet it shows something - the entities we would call facts if "fact" were not a formal concept. The case of counterfactuals, however, is different. There would be no counterfactual facts even if we could say that there are other facts. Why then do we attribute truth to some and falsehood to other counterfactuals? The concept of "fact" is useful because of its connection with the concept of truth. Counterfactuals also enjoy that connection - but not directly, as true indicative sentences do. We take "If I put this spoonful of sugar in water, it would eventually dissolve," to be true, and "If I put this spoon in water, it would eventually dissolve" as false. The reason is not that the former corresponds to a counterfactual fact, while the latter does not, but that some sentence in what Quine would have called the intruding stabilizing factor in the case of "If I put this spoonful of sugar in water, it would eventually dissolve" is true.

Facts and truth an antirealist interpretation of counterfactuals does not claim that no counterfactuals are true. It claims that their truth is not due to there being corresponding things or facts in the world that would be there even if there were no counterfactuals. This is evident in the case of logically true counterfactuals, for it is evident that logical expressions, the essential parts of logical truths, do not stand for objects, that there are no such things as and, or, and all in the world and therefore no logical facts. Nonetheless, logically true counterfactuals are true.

This conclusion may seem unsatisfactory. We may still ask, "What makes true counterfactuals true?" But then we may also ask, "What makes logical truths true?" The answer to both questions is, "Nothing." When Wittgenstein asserted "There are no 'logical objects," he did not merely mean that "object" is a formal concept. There are no such things as and or all to be even shown. We may find this answer in the case of counterfactuals less unsatisfactory if we recognize that we usually do not find it unsatisfactory in the case of logical truths. If we focus on causal statements as the most important, though implicit, kind of counterfactuals, we may state our conclusion by saying that logical and causal judgments are the two great kinds of cognition - logic/mathematics and science - and that explaining them further by imagining realities corresponding but external to them is just that: imagination.

If we free ourselves from the confines imposed by any one of the usual theories of truth, we may see that the question about what makes true sentences true ignores the complexity, subtlety, and wide range of the use of the word "true." We should rather speak of the features, relational or nonrelational, of the context in which a sentence is taken to be true, and acknowledge that these features are many and diverse.

The several "theories" of truth emphasize different uses of "true," and each is plausible in its own way. Some sentences, most notably those reporting observation, are taken to be true in virtue of surviving what Quine called confrontation with sense experience. Their case lends support to the standard correspondence theory of truth. Some simple mathematical sentences perhaps are taken to be true in virtue of surviving confrontation with intellectual intuition, a priori insight. But most mathematical sentences and all theoretical sentences in science are taken to be true mainly, if not solely, in virtue of their membership in systems that survive confrontation with experience or with reason. Their case lends support to the theories of truth as "coherence" and as "idealized warranted assertability." Sometimes sentences are accepted only because they belong to theories judged more "beautiful" or "elegant" than their alternatives. Their case could have given rise to an aesthetic theory of truth.

And sentences like "I will be alive tomorrow" are accepted by the speaker, at least tacitly, as true mainly, if not solely, for practical reasons. Their case perhaps lends support to the "pragmatic" theories of truth. In ordinary, not all, circumstances, I do not consider whether the sentence "I will be alive tomorrow" is true, but of course "take" it, however implicitly, to be true. I do so neither on the basis of experience or reason, nor because it coheres with other sentences. If I appealed to experience, reason, or coherence, I might not take it to be true, certainly not as unquestionably true - and as a result perhaps suffer disastrous consequences today, or at least postpone paying the life insurance premium due today until tomorrow. Rather, I take it to be true insofar as it is presupposed by 
virtually everything I do and plan today. My life today would be radically different if I did not have unquestioning faith that it will continue for at least one more day. Acceptance of the sentence "I will be alive tomorrow" is thus practically necessary, while the acceptance of some sentences of mathematics and science may be said to be theoretically necessary, and the acceptance of some observation sentences ("It's hot!") perhaps palpably necessary.

The word "true" is versatile enough to allow without equivocation for such diversity in what "makes" sentences true. The ways of knowledge and truth are not neat and tidy. This is especially evident in ethics. "True" does resemble "good" in this respect. Gustatory pleasure, knowledge, compassion, right conduct, and justice are all standard examples of good things, but they seem to have little else in common. Yet there is no equivocation in calling all of them good. The moral, however, is not that we should accept noncognitivism regarding goodness. A doctor's orders are imperatives, and thus cannot be said to be true, but usually their legitimacy and authority are unquestionably cognitive because their ground is usually cognitive. Theology often grounds the authority of God in his omniscience, not his status as our creator, but ordinary religious thought usually holds the latter to be a sufficient ground. It is in this second way, presumably, that the authority of what Kant called practical reason (Vernunft) and his description of ethical judgments as both imperatives (Imperative) and cognitions (Erkenntnisse) should be understood[24]. If so, perhaps we should call ethical judgments "valid" rather than" true," as Kant indeed often did. They would be valid in the sense in which we call valid both a doctor's orders and the propositions grounding them. But ethical judgments can be valid also in the sense in which a traffic policeman's telling us to move to the other lane of the street is (sometimes) valid. We may follow Nelson Goodman and just use "right" for all four: ethical judgments, a doctor's orders, the propositions grounding those orders, and the traffic policeman's orders.

Similarly, the moral to be drawn from the diversity of the uses of "true" is not that we should stampede into a theory of truth that renounces correspondence to fact altogether. Even in the case of the earlier mentioned generic statements, where neither correspondence to fact nor coherence or practical utility suffices for truth, all three are relevant. "Dutchmen are good sailors" is taken to be true because a "sufficient" number of singular statements of the form "x is Dutch and $x$ is a good sailor" are taken to be true, usually on the basis of direct observation. But how many such statements suffice would depend on how the generic statement coheres with various other statements - about sailors, ships, shipping lanes, marine weather, piracy, the presence of men-of-war protecting merchantmen. And its truth would depend also on practical considerations, best known to shipmasters and ship owners, such as the purpose of most sailings, the value of cargoes, the availability and cost of labor at the docks.

This is why the various theories of truth are all legitimate. The truth of "I have a headache" is plausibly viewed as correspondence, if not to a "fact" then to a "thing": the ache felt in the head. But even though many sentences can be paired off with bits of the world in this way, most cannot, including some that especially interest us. Counterfactuals like "If Hitler had not invaded the Soviet Union, Germany would have won the Second World War" are obvious examples. But so are also complex, largely dispositional sentences like "She liked him, admired his intelligence, was attracted to him, but did not love him because he reminded her of her father." The truth of such statements is better viewed as their coherence with a vast number of other sentences. And many sentences about the future, like "I shall be alive tomorrow," are surely taken as true because the speaker must accept them in order to engage in normal activities today. No account of truth should fail to note such differences between true sentences, such kinds of truth.

Ascribing truth to some counterfactuals even when aware that there are no counterfactual facts is thus not extraordinary. As Quine suggested, the explanation is the presence of one or more true sentences in the context of the counterfactual. Hume regarded the counterfactual statement "if the first object had not been, the second never existed" as true because of the truth of "all the objects similar to the first are followed by objects similar to the second," the "constant conjunction" of the former and the latter. For Kant, the category of cause required a "schema," which in effect was what Hume called constant conjunction [25].

24 Immanuel Kant, Critique of Practical Reason, trans. Lewis White Beck (Indianapolis: BobbsMerrill, 1956), 68.

${ }_{25}$ Critique of Pure Reason, A 144/B 183. 